\title{
FAZER-SE ESTADO A PARTIR DAS FRONTEIRAS: circulação de corpos, objetos e significados entre os muros da prisão
}

\section{THE MAKING OF ONESELF IN THE STATE FROM THE BORDERS: the circulation of bodies, objects and meanings between prison walls}

\author{
Francisco Elionardo de Melo Nascimento* \\ Roberto Marques $^{* *}$
}

\begin{abstract}
Resumo
Este artigo discute as fronteiras da prisão definidas nos pontos de verificações que controlam os fluxos e circulações de pessoas, objetos e informações. A partir das performances e narrativas que estabelecem porosidades entre o dentro e fora das prisões, discutimos processos de Estado dispostos nas regras, normas e regulamentos que se desenrolam na exigência de documentações, revistas e vistorias de corpos e materiais, atravessados por marcadores de diferenças de gênero, sexualidade e classe. Fontes de dados e metodologias alternativas permitem-nos pensar as fronteiras do Estado como performance de composição do Estado e produção de subjetividade das pessoas por ela implicadas.
\end{abstract}

Palavras-chave: Prisões. Fronteiras. Processos de Estado. Gênero.

\begin{abstract}
This article is concerned with the boundaries between the inside and the outside of prisons. It is part of a broader ethnographic research on the imprisonment of transvestites in Ceará. Here, observing the porosities of prison, we address the boundaries defined in the checkpoints that control the flows and movements of people, objects, and information. Therefore, we intend to discuss the processes of state crossed by social markers of difference - such as gender, sexuality, and class - and embedded in the rules, norms, and regulations deployed in the requirement of documentation, searches, and inspections of bodies and materials. Alternative sources and methodologies allow us to think of the borders of the state as performances of composition of the state and understand the production of subjectivity of the people involved in that process.
\end{abstract}

Keywords: Prisons. Borders. State processes. Gender.

\section{Introdução}

As fronteiras, cada vez mais borradas, entre o prisional e o urbano têm tensionado o paradigma clássico de pensar as prisões como "instituições totais" (GOFFMAN, 1987). A perspectiva que se empenha em verificar a potencialidade analítica de pensar a continuidade entre o dentro e fora das instituições prisionais destaca as variadas formas de conexão presentes nos fluxos penitenciários (GODOI, 2015b); na porosidade econômica e administrativa (CUNHA, 2008); no trânsito incessante de corpos entre as muralhas e o mundão (MALLART; RUI, 2017); nas ligações atravessadas por redes afetivas e relações de ajudas que permeiam as prisões (PADOVANI, 2018). A variedade de conexões citadas é acompanhada de perto por processos de gestão das circulações, materializados em diversos pontos de verificação e controle de entrada e saída de pessoas, objetos e informações.

\footnotetext{
* Doutorando e Mestre em Sociologia pelo PPGS/UECE, Agente Penitenciário do Ceará e membro do Laboratório de Estudos Conflitualidades e Violência (COVIO/UECE). E-mail: elionardomelo@gmail.com

** Docente do PPGS/UECE. Doutor em Antropologia Cultural pelo PPGSA/UFRJ, com estágios pós-doutorais junto a essa instituição e ao PAGU/Unicamp. E-mail: r-marques01@uol.com.br
} 
A inscrição dessas instituições no tecido social (GODOI, 2015b) é marcada, portanto, pela reflexão sobre os vários mecanismos de normalização, controle e regulação dos trânsitos instituídos pelos processos de Estado que legitimam ou não os fluxos. Expedientes que implicam a existência de postos e "procedimentos" de verificação específicos. Estabelece-se neles e a partir deles, portanto, um campo de relações e práticas que mobilizam múltiplos atores indispensáveis para o funcionamento cotidiano das prisões, que se desdobram em relações de cumplicidade e/ ou conflito entre presos, seus familiares e amigos, agentes estatais e outras instituições ligadas ao aprisionamento.

Para Godoi (2015a), a visita seria um dos principais "vasos comunicantes" da prisão, por isso, alvo primordial das regulações e restrições de acesso de pessoas, objetos e informações pelo governo penitenciário. A noção de vaso comunicante se refere a qualquer "forma, meio ou ocasião de contato entre o dentro e o fora da prisão" (GODOI, 2015b, p. 136). As fronteiras são evidenciadas, assim, pelos postos de verificação e controle instalados entre o fora e o dentro das unidades prisionais. Nestes locais, os fluxos de pessoas, objetos, informações, sentimentos e ideais (retidos ou não) não são desprovidos de bloqueios, negociações, relações de poder e disputas.

Esse conjunto de preocupações dos estudos prisionais revisita argumentos da obra seminal de Michel Foucault (1997) que caracteriza a emergência da "época clássica” pela modificação da escala na regulação dos corpos, recrudescendo discursos que ordenam e definem as instituições a partir de horários, espaços, relações e procedimentos cotidianos (p. 132-133). Lugares de trânsito, como portos, alfândegas e hospitais militares, seriam espaços potenciais de contágio. Neles, a habilidade de separar, definir, administrar está sendo posta em xeque, demandando ação e presença contínua do Estado. Essa ação estabelece descontinuidades, reiterando a existência de unidades discretas idealmente perceptíveis em si mesmas. Para Butler (2008), as ideias reguladoras que nos fazem perceber diferenças materiais entre unidades discretas como concepções autoevidentes dependem da reiteração de práticas capazes de instaurar tais juízos como naturais.

Cotejando as ideias de Foucault e Butler citadas acima com o caráter polissêmico das noções de fronteira (CARDIN; ALBUQUERQUE, 2018; ALBUQUERQUE; OLIVAR, 2015), buscaremos demonstrar a natureza performativa das operações de revista de visitantes nas prisões do Ceará. Aqui, observar as fronteiras físicas do Estado é etnografar suas práticas institucionais através de performatividades cotidianas.

Ao mobilizar esforço físico de agentes e visitantes, tecnologias e expedientes em prol da disciplinarização de fluxos de pessoas e objetos na prisão, o Estado produz diferenciações polarizadas entre o mundo do crime e a instituição punitiva; facções e estado; criminosos e agentes. Tal polarização é materializada nas regras burocráticas de entrada e saída de objetos e pessoas, pelo esforço e cansaço dos agentes prisionais, pela aparência de rigor, ordem e disciplina. Desse modo, corpos e regras acionam um modo de relação fora x dentro, 
inscrevendo eventuais equívocos nessa engenharia como exceções das técnicas supostamente rigorosas do Estado.

No apanágio aqui descrito, a noção de fronteira aparece em dupla função: como dispositivo fundamental para reiteração da existência do Estado pela materialização da diferença lei $\mathrm{X}$ mundo do crime, e como espécie de entreposto a partir de onde o Estado insinua seu controle e avanço. Fronteira, aqui, é esse espaço de contato e tensão (DAS, 1995; FELTRAN, 2011) entre lugares de onde o Estado olha a si mesmo para constituir-se como diferença não dada a contágios. É também o lugar onde dá-se a ver, performatizando essa diferença e institucionalizando uma percepção desejável de si.

Buscaremos demonstrar, portanto, como a partir de normas e regulamentos realizados nas exigências de documentações e vistorias de corpos e materiais nas entradas da prisão, o Estado desenvolve uma ação performativa que eclode noções de rigor entre o dentro e fora das prisões. Tais regras mobilizam marcadores de diferenças de gênero, sexualidade e classe, produzindo relações fortemente generificadas entre os agentes envolvidos: presos, visitantes, agentes penitenciários e facções.

As reflexões aqui desenvolvidas decorrem de pesquisa etnográfica mais ampla que discutiu o aprisionamento de travestis no Ceará (NASCIMENTO, 2018) ${ }^{1}$. Como desenvolveremos a seguir, uma mirada a partir da presença das travestis no espaço da prisão, usualmente definida pela presença masculina heterossexual (PADOVANI, 2018; LAGO; ZAMBONI, 2017), potencializa um olhar crítico sobre os processos de Estado (LIMA, 2002) e a suas formas de generificação.

O artigo está organizado a partir de duas empreitadas metodológicas. Na primeira parte, descreveremos as regulações de entrada e atitudes diárias entre visitantes e agentes ao longo das vistorias ocorridas na Penitenciária Industrial Regional de Sobral (PIRS). Na segunda parte do artigo, debruçaremos-nos sobre os dados oficiais a respeito do material ilícito recolhido nas unidades prisionais do Ceará entre os anos de 2014 e 2016. O cotejamento das informações oriundas das duas metodologias descritas nos possibilitará pensar o lugar das revistas na construção de uma gramática sobre as fronteiras das prisões e do Estado.

Vale chamar atenção ainda que a escrita do artigo $^{2}$ se encontra enredada em um mundo que agencia corpos masculinos e femininos como diferenças, percepção particularmente evidente na demanda de descrições sempre generificadas dos personagens aqui relatados. Como discutiremos a seguir, por vezes as incontornáveis marcações de gênero precipitadas pela escrita emergiam em termos que seriam meramente descritivos, fazendo-nos perceber mútuas e complexas implicações entre gênero e Estado (VIANNA; LOWERKRON, 2017). Nesse contexto,

1 Os dados etnográficos apresentados foram coletados entre 2016 e 2018. A partir de 2019, mudanças de gestão nas unidades e a criação da Secretaria de Administração Penitenciária alteraram drasticamente o cenário das prisões cearenses. As mudanças ocorridas estão descritas em Nascimento e Freitas (2019). Esta pesquisa contou com financiamento da Fundação Cearense de Apoio ao Desenvolvimento Científico e Tecnológico (FUNCAP).

2 Sobre a escrita etnográfica como materialização de relações de poder a que o texto se encontra submetido ver: Clifford (2002) e Marcus e Cushman (1982). 
uma metodologia que evidencia a errância de gênero e sexualidade materializada a partir das falas de travestis (BUTLER, 2008; SPIVAK, 2010) nas prisões masculinas nos auxilia a lançar novas luzes sobre as fronteiras das prisões, suas performances e narrativas.

\section{Na entrada da prisão}

Os dias de visita nas penitenciárias cearenses seguem o mesmo ritual. Ainda na véspera, mulheres começam a acampar em frente às penitenciárias no intuito de garantir seus lugares na fila. Sem espaço adequado para guarida, na Penitenciária Industrial Regional de Sobral, as visitantes armam suas redes nas árvores que ficam em frente à unidade prisional e se revezam por toda a madrugada em vigília para se protegerem de possíveis ameaças, como ataques de animais silvestres, furtos dos pertences pessoais e de seus "malotes".

A PIRS é uma penitenciária masculina para presos em cumprimento de pena privativa de liberdade em regime fechado. Foi inaugurada em 2002 e tem capacidade para 492 internos. No período da pesquisa, a unidade abrigava uma população prisional que variava entre 650 a 700 presos $^{4}$. A equipe profissional da unidade é composta por quatro equipes de dez agentes penitenciários plantonistas. A penitenciária está localizada a aproximadamente seis quilômetros do centro da cidade de Sobral, a 240 quilômetros da capital Fortaleza, às margens da rodovia CE 187 e em meio à vegetação de caatinga. Não há residências nos arredores. Ali, o fluxo de carros, motos e pedestres é intenso e exige das visitantes alguns cuidados para evitar possíveis acidentes.

A entrada das visitantes nas celas é permitida às quartas e aos domingos, das sete e trinta às dezesseis e trinta. Assim, grupos de mulheres com diferentes graus de parentesco com os homens ali detidos se deslocam de vários bairros periféricos de Sobral e cidades circunvizinhas em direção à penitenciária, carregando seus pesados "malotes", e se aglomeram em frente ao portão de entrada. São mães, companheiras, tias, filhas. As mais experientes - muitas há décadas seguindo esse percurso - instruem as novatas a respeito das regras impostas pela administração prisional e também as estabelecidas no convívio dos presos e das visitantes. Naquele espaço são construídas redes de relações, cumplicidade, rivalidade, fofocas e afetos que extrapolam o cenário prisional e se desenrolam nos bairros e sítios daquelas pessoas. Segundo algumas entrevistadas, todo esforço para estar entre as primeiras da fila é recompensado com o tempo mais extenso na presença do interno visitado.

A paisagem das relações constituídas entre profissionais, internos e visitantes foi profundamente modificada com a expansão de grupos criminais criados em outras regiões do

3 Malotes são enormes sacolas contendo roupas, material de higiene pessoal e limpeza, alimentos, medicamentos, água potável, toalhas, lençóis, colchão, entre outros itens estabelecidos pela administração penitenciária. No Ceará, o deslocamento de familiares até as unidades prisionais com os "malotes" é a única forma de fornecer os produtos necessários à sobrevivência na prisão.

4 Todas as unidades prisionais do estado do Ceará trabalham com enorme excedente de presos, tornando bastante precárias as condições de vida nessas instituições. Os dados produzidos pelo Departamento Penitenciário Nacional, referentes ao ano de 2016, mostram que a população prisional do Ceará era de 34.566 pessoas para 11.179 vagas. 
Brasil e instalados no Ceará a partir de 2014. O Primeiro Comando da Capital e o Comando Vermelho, vindos do Sudeste, e a Família do Norte, originária dessa região, são os principais grupos criminais que atuam dentro e fora das prisões cearenses. Registra-se ainda a presença de uma facção local que reivindica o status de Guardiões do Estado, opondo-se à presença de facções estrangeiras (SÁ; AQUINO, 2018; PAIVA, 2019; NASCIMENTO, 2019).

$\mathrm{O}$ dia amanhece. Em meio à vegetação seca e o solo rachado, o sol espraia suas primeiras rajadas de luz e protagoniza um calor escaldante. A fila extensa em frente à unidade prisional estende-se por seu entorno, sendo rigidamente organizada pelas primeiras mulheres que ali chegaram. Ao lado desta, uma segunda fila formada por pessoas que têm acesso prioritário: idosas, deficientes, gestantes e mães com crianças de colo. A entrada de crianças com até doze anos é permitida na PIRS, se acompanhadas pela mãe ou responsável legal, enquanto a visita de familiares do sexo masculino é permitida no segundo e no quarto sábado de cada mês, das oito horas ao meio-dia. Assim, reitera-se participações distintas de homens e mulheres, adultos e crianças nos cuidados com presos e presas (STRATHERN, 1995); iteração justificada a partir de imagens de fácil circulação no imaginário que cerca a prisão: a mãe ou esposa que não abandona seu filho; a necessidade da visita íntima para a perpetuação do casal; a parceria perigosa entre homens que atravessam a fronteira entre o dentro e o fora da prisão.

Um pouco mais afastada do portão de entrada fica uma barraca que vende itens variados: produtos de limpeza, artigos de higiene pessoal, roupas, frutas, biscoitos, pães, leite e refresco de frutas em pó. Juntos, os elementos aqui descritos formam um amontoado de pessoas e objetos. Conversas paralelas, discussões e choro de crianças são misturadas ao barulho intenso do vai e vem dos carros que seguem pela estrada. Cada visitante tem cuidados redobrados para manter suas sacolas fechadas e à vista, pois há sempre o receio da subtração de itens e/ou de "cruzeta", cilada orquestrada pela inserção de mercadorias ilícitas nas sacolas de outra visitante que pode configurar-se em contravenção penal. Às seis horas da manhã, Marcela ${ }^{5}$, agente penitenciária plantonista na recepção, segue em direção à entrada da unidade, distribui as senhas e logo toda a fila se desfaz.

Impacientes e fadigadas pelo cansaço, espera e calor escaldante, as visitantes aguardam o início da "vistoria dos malotes". Na recepção, Marcela chama um grupo de dez visitantes e confere os documentos necessários para a entrada na unidade. Após verificar a validade e a autenticidade da identidade e carteirinha, a agente marca com um X o nome da visitante identificada em uma lista onde constam todas as pessoas aptas à visitação naquela unidade.

Para solicitar a carteirinha que autoriza a visitação na PIRS, há a exigência de documentos comprobatórios de acordo com o vínculo que o/a requerente tem com o interno. Documentos específicos e comuns são exigidos para mães, pais, companheiras, irmãos, irmãs e filhos. Todos devem apresentar cópias autenticadas da identidade, CPF, Certidão de Antecedentes Criminais emitida por fórum da cidade, cartão do SUS e cópia de algum documento do interno, além de

5 Utilizamos aqui nomes fictícios a fim de preservar as identidades de interlocutores e interlocutoras. 
duas fotos $3 \times 4$ recentes. Especificamente para companheiras que não dispuserem da Certidão de Casamento Civil ou prole registrada com o nome do interno, é obrigatória a apresentação de declaração de convivência conjugal emitida por cartório, documentos que tornam legíveis relações mantidas com pessoas, redes e lugares externos à prisão (PADOVANI, 2018), ou seja, é preciso provar ao Estado a legitimidade das relações constituídas a partir da conjugalidade e parentalidade, bem como atestar a negatividade de antecedentes criminais. Todos os documentos são objeto de exame pelo setor de Serviço Social, seu bom estado e autenticidade são observados e conferidos por profissionais especialmente destacados para essa atividade. Embora a Lei de Execução Penal não exija vínculo familiar como pré-condição para a visitação, esse critério foi descrito por meio de normativas no âmbito da Secretaria de Justiça e Cidadania do Ceará que versam sobre o assunto. Tal vínculo deve ser comprovado por documentos específicos que tragam marcas de legitimidade, como carimbos, timbres, selos e assinaturas.

De acordo com Padovani (2018), os laços familiares e afetivos constituídos entre o dentro e o fora das prisões por esposas e maridos, amantes, mães e pais testam aqueles reconhecidos pelo Estado. Todo o esforço em produzir, legibilizar e legitimar documentos com selos de autenticidade oficiais gera esforço e desgaste físico para as pessoas que pleiteiam a visitação na prisão. Esses documentos nada mais são que processos burocráticos que definem quem entra, sai ou fica retido nas prisões. A obrigatoriedade da confecção, legitimação e apresentação desses documentos, com a finalidade da concessão da visita, lembra-nos os argumentos de Das e Poole (2004) sobre o exercício de poder e controle do Estado constituído por procedimentos escritos que enfatizam algumas características em detrimento de outras.

Após a verificação da documentação, forma-se outra fila para a "vistoria dos malotes". Uma lista fixada na parede da recepção versa sobre os itens permitidos, as quantidades e formas de acondicionamento autorizadas.

\section{Vistoria dos "malotes"}

Uma bancada metálica de três metros de comprimento está posicionada à frente da nova fila que se forma. Do outro lado da bancada, quatro agentes designados para a "vistoria dos malotes" executam a tarefa chamando uma visitante por vez. Na bancada, cada item é retirado das sacolas e passa a dividir espaço com os objetos que auxiliam os profissionais na execução da tarefa: garfo, faca, balança e sacos plásticos transparentes. Cada mercadoria requer um modo particular de verificação. Abrir, desembalar, cheirar, fatiar, descascar, furar, aferir a quantidade, a forma de acondicionamento e separar itens "permitidos" dos "proibidos" são tarefas que ocuparão todo o dia de trabalho dos agentes.

O refrigerante deve ser de sabor laranja, limão ou guaraná - nunca de cor escura. Seu rótulo é retirado, o frasco é aberto e cheirado para constatar a ausência de outras substâncias. As frutas são descascadas, fatiadas e colocadas em sacos plásticos pela visitante diante da supervisão 
do profissional. A manipulação das frutas é objeto de constantes discussões. As visitantes alegam que a retirada da casca da fruta diminui o tempo hábil para consumo. A exigência é justificada pelo que os agentes prisionais costumam chamar "finalidade secundária" do produto, ou seja, sua utilização para a produção do "goró" - cachaça artesanal comumente apreendida no interior das celas. A comida pronta, feijão, arroz, carne e legumes, deve ser posta em um recipiente plástico transparente. É permitido apenas um reservatório por visitante. A comida não pode ser pastosa, a carne é desossada e todo o conteúdo deve pesar até dois quilos. Ao vistoriar o vasilhame, o agente remexe tudo com o auxílio de garfo e faca. Os produtos de higiene pessoal e limpeza são criteriosamente apalpados e devem estar acondicionados em embalagens também transparentes. Sabonetes são furados ou cortados ao meio, sob a suspeita de conterem aparelhos celulares, carregadores ou chips. Os demais itens seguem análise semelhante de controle da quantidade, verificação e forma de acondicionamento. A "vistoria dos malotes" causa constantes conflitos entre visitantes e agentes, tanto em função dos critérios impostos como pela forma como os itens são manipulados.

Após muitas horas de trabalho intenso na "vistoria dos malotes", o semblante de cansaço decorrente das mais de quarenta e oito horas de plantão é notório em todos os profissionais. $\mathrm{O}$ cansaço determina o compasso da atividade, desempenhada cada vez mais lentamente. Mães e esposas, cada uma por vez, dirigem-se à bancada com suas sacolas de tamanhos e conteúdos variados. Os mantimentos trazidos nas sacolas proporcionarão aos reclusos o mínimo de condições materiais para "puxar cadeia" por alguns dias.

Dona Sandra, mãe de Renata - travesti que cumpria pena por tráfico de drogas na PIRS - afirmou o quanto era difícil a rotina de visitação na unidade prisional. Sandra dispendia todas as suas forças para garantir que sua filha tivesse o mínimo para sobreviver.

É muito difícil seguir nesta vida de cadeia. Já fazem mais de oito anos que Renata tá presa, mas eu sigo na luta pra vir deixar as coisinhas dela. Eu cato reciclagem a semana toda com meu esposo pra poder vir visitar ela. Essa sacolinha de coisas aqui me custou mais de cinquenta reais e era o dinheiro que eu tinha apurado na semana.

Assim como Dona Sandra, outras visitantes relataram suas dificuldades e limitações financeiras, mas que sempre arranjavam um "jeitinho" de continuar trazendo os "malotes". A rotina semanal dessas mulheres gira em torno das visitas: quartas e domingos inteiramente comprometidos com "os protocolos de entrada e ao retorno das unidades, e com os demais dias a serem geridos entre os cuidados com os filhos, o trabalho, os afazeres domésticos, o lazer e as atividades próprias da preparação da visita" (GODOI, 2015a, p. 180). Terminada a "vistoria do malote", a visitante é separada de sua mercadoria e outra fila se forma, a do controle dos corpos - a "revista pessoal" obrigatória ou "vexatória", como denominam os movimentos sociais que reivindicam a extinção desta prática nas unidades prisionais. A visita na prisão está implicada em uma série de regulações particulares para cada um dos momentos acima descritos. Sendo 
predominantemente composta por mulheres, elas são alvos de grande parte dos processos, controles e normas de Estado que firmam a prisão como dispositivo (FOUCAULT, 1997).

\section{Controle dos corpos}

Na fila, enquanto aguardam a "revista pessoal", as visitantes trocam informações sobre a indumentária considerada adequada para a entrada naquela penitenciária, contam situações jocosas ocorridas em vistorias anteriores, falam sobre que objetos são permitidos e, muitas vezes, socializam estratégias de como burlar as regras divulgadas pela administração prisional em torno das vestimentas das visitantes.

As vestimentas das mulheres são esquadrinhadas pelas agentes penitenciárias. As profissionais são responsáveis pela revista de pessoas do sexo feminino que adentram as unidades prisionais, conforme o normatizado pelo Regimento Geral dos Estabelecimentos Prisionais do Ceará (CEARÁ, 2010). Em hipótese alguma é permitida a entrada para a visitação na unidade de pessoas com roupas e calçados de cores escuras ou que tenham algum detalhe metálico. Tal proibição é uma forma de diferenciar o traje de ingressantes do fardamento dos agentes. Calças leggings, blusas de algodão/lycra e chinelo havaianas dão o tom de uniforme padrão. Contudo, cores e modelos das vestimentas permitidas podem mudar a qualquer momento, justificadas pelas tentativas frustradas de transgressão às normas ou por transtornos anteriores ocorridos entre profissionais e internos. Durante a imersão na PIRS, observou-se que o uso de roupas curtas ou que marcam os corpos das visitantes provocava conflitos entre visitantes, agentes prisionais e internos. Esses conflitos serviram de prerrogativa para proibições, principalmente de roupas consideradas transparentes. Uma profissional responsável pela vistoria relatou que, certa vez, um dos presos acusou um agente de ter "brechado" o corpo de sua esposa e, por isso, ameaçou-o de morte. A frequente mudança de modelos e cores das roupas, "permitidas" e "proibidas", deflagra tensão entre agentes e visitantes e inspira redes de ajudas, trocas de informações, aluguel e venda de roupas em frente à unidade.

No Ceará, a "revista íntima" foi proibida em agosto de 2014. A proibição teve como principal fundamento o respeito à dignidade humana, vedando qualquer forma de desnudamento, tratamento desumano ou degradante de visitantes, internos, servidores, profissionais ou autoridades que ingressem nas unidades prisionais do estado. O "procedimento" passou a ser chamado "revista pessoal", realizado de forma eletrônica; mecânica ou manual, tendo uso prioritário de detector de metais, escâner corporal, aparelhos de raio X ou similares. A nova forma de revista passou a ser realizada em todas as unidades prisionais que são de responsabilidade da Secretaria de Justiça e Cidadania. A “revista íntima” ou "vexatória” era realizada sob a justificativa de inibir a entrada de materiais "ilícitos" carregados nas roupas ou inseridos nas cavidades das visitantes. 
Em pesquisa realizada na PIRS, Nascimento (2015) descreveu o "procedimento" adotado antes da nova normativa estabelecida para as revistas, que consistia em: entrar em uma sala reservada, retirar todas as vestimentas e entregá-las nas mãos da agente para verificar a presença de "ilícitos" nas costuras e dobras. Em seguida, abrir a boca, levantar e movimentar de um lado ao outro a língua, erguer os braços para verificação das axilas, espalmar as mãos, mexer nos cabelos e levantar os seios um a um. Totalmente despida, a visitante era posicionada com um espelho circular por entre suas pernas e por três vezes consecutivas era instruída a se agachar soprando o pulso ou forçando o ato de tossir, o que expulsaria possíveis objetos e/ ou materiais inseridos no ânus e vagina. A partir da imagem refletida no espelho, a profissional responsável visualizava o órgão genital e excretor. Ao relembrar a execução do "procedimento", Dona Sandra comentou sentir intenso constrangimento durante a "revista vexatória": "Eu já não conseguia me agachar no espelho e as agentes colocavam pra eu sentar na cadeira nua e abrir as pernas. Era muito constrangimento". Em conversas ao longo do trabalho de campo, as agentes penitenciarias classificaram a prática como bastante invasiva.

A proibição da "revista íntima" nas unidades prisionais do Ceará foi alvo de intensas críticas por parte dos agentes penitenciários, que diante da ausência de equipamentos eletrônicos adequados para a realização do "procedimento", reclamavam dos riscos da prática para a segurança dos profissionais e dos próprios presos nas celas (NASCIMENTO, 2015).

De acordo com Godoi (2015a), a "revista vexatória" "pode ser considerada um ritual de degradação que marca a passagem do mundo livre ao prisional, assinalando no corpo da visitante (...)absoluto assujeitamento aos desígnios da administração penitenciária” (p. 188). A partir da experiência das revistas em mulheres presas, Angela Davis (2009) ironiza a divisão convencional entre prisão e sociedade que, de certa forma, coaduna-se ao assujeitamento de mulheres com a prática da "revista vexatória" nas prisões brasileiras.

\footnotetext{
Reconhecemos o fato de que as presidiárias do mundo todo são forçadas regularmente a passar por revistas, nuas, em suas cavidades. Isso quer dizer que suas vaginas e retos são vasculhados. Qualquer mulher capaz de se imaginar - não de imaginar outra mulher, e sim ela mesma - revistada de tal maneira interpretará isso como abuso sexual. Mas, como isso ocorre nos presídios, a sociedade supõe que esse tipo de agressão é um aspecto autojustificado pelo simples fato do aprisionamento. A sociedade supõe que é isso que acontece quando uma mulher é presa. Que é isso que acontece à cidadã privada de seus direitos civis e que, portanto, está certo que a prisioneira seja submetida à coerção sexual (DAVIS, 2009, p. 54-55).
}

Tais posicionamentos espelham o enunciado de Foucault (2015) para quem o penitenciário tramou-se através da prisão, tendo como fundamento e condição de estabilidade a coerção. Sem dúvidas, a "revista vexatória" é objeto de inúmeras disputas políticas e tensões cotidianas entre agentes penitenciários, administração prisional, visitantes e pessoas em cumprimento de pena, bem como ativistas de organizações não governamentais, políticos e demais atores dessas 
arenas. Como consequência desses debates, desde abril de 2016, as "revistas vexatórias" "em mulheres" estão proibidas em todos as penitenciárias brasileiras.

Em 2014, a Secretaria de Justiça e Cidadania do Ceará iniciou a compra de equipamentos de escâner corporal semelhantes aos utilizados em aeroportos. Em 2016, todas as grandes unidades prisionais já dispunham deste equipamento. A partir de então, cada visitante passa pela revista feita eletronicamente. O escaneamento é exibido em um monitor e analisado por um profissional do mesmo sexo que a pessoa ingressante. Na tela, substâncias são identificadas a partir de cores de tonalidades diferentes realçando os "materiais ilícitos" e facilitando o controle de substâncias levadas por visitantes.

Com a utilização dos equipamentos eletrônicos, o Estado massifica o controle, regulação e forma de verificação do que entra e sai das prisões. Toda a dinâmica de controle das fronteiras da prisão pode ser reorientada por práticas dos agentes penitenciários, responsáveis diretos pelos postos de verificações. Em algumas unidades prisionais, esses profissionais operam com rigidez intransponível nos "procedimentos" - a exemplo das grandes unidades prisionais. Em outros postos fronteiriços, apresentam tolerância, flexibilidade e pouca presença.

"No meio de Estados multiformes, ambivalentes e carnalmente enredados (...)" (OLIVAR, 2015, p. 166), as regulações de fronteiras em grandes unidades prisionais e cadeias públicas passam a ser agenciadas pelas práticas entre agentes prisionais e visitantes. Os primeiros, personagens históricos das prisões que herdaram algumas atribuições dos carcereiros, são eles próprios a encarnação do Estado multidimensional, volátil e composto de normas ambivalentes. Readaptam suas formas de agir no cotidiano e nas relações conturbadas com visitantes e internos, observando imediatamente as adequações e os limites legais que entrelaçam relações de poder, hierarquia e negociações junto aos apenados. As visitantes, por sua vez, movidas por elos afetivos, produzem diversas linhas de fuga das regras produzidas por e nos postos fronteiriços, lançando mão da cordialidade para tentar garantir condições mínimas para seus familiares "puxarem cadeia”.

A produção de normas de Estado está fortemente marcada por gênero, sexualidade, classe e assimetrias de poder nas relações entre agentes penitenciários, visitantes e presos. A prisão é o próprio Estado materializado. Nela, sua soberania é exercida não apenas sobre o território - espaço físico da instituição com suas normas e regras -, mas também sobre os corpos das pessoas que trabalham, visitam ou que ficam presas. Dessa forma, as fronteiras da prisão tornam-se espaço privilegiado de produção discursiva e sociopolítica do governo penitenciário. É o governo penitenciário que gesta os fluxos de pessoas e objetos, produz e mobiliza processos multidimensionais de controle do que entra, sai ou fica retido nas fronteiras da prisão.

Terminado o "procedimento", a visitante tem sua entrada liberada e segue por um extenso corredor cercado por alambrados, grades e fossos. Ao chegar ao Quadrante 1- Q1 ${ }^{6}$, mais uma

6 Q1 é a demarcação simbólica e física do limite estabelecido para o trânsito de presos que desenvolvem alguma atividade laboral no interior da unidade prisional. Ali, os presos aguardam advogados, assistentes sociais, psicólogos ou atendimento de saúde. Ali encontra-se um agente penitenciário plantonista que controla o fluxo de pessoas e objetos na unidade. 
vez, os/as ingressantes são identificados a partir de uma lista com os nomes das pessoas cuja visitação foi permitida. Suas carteirinhas são recolhidas e dali seguem percurso rumo às alas.

Em frente à entrada da ala, um último posto de verificação é acionado. Ali, dois agentes penitenciários estão encarregados de identificar onde o preso está alocado a partir do número grafado no verso de cada uma das senhas e, em seguida, abrir o portão de acesso. A ação destes profissionais se repete durante todo o dia de visita em meio aos quase 700 internos e do fluxo frenético de entrada e saída de pessoas. No cenário de trabalho repetitivo, superlotação e parco contingente de agentes, resta-lhes um intenso jogo de negociação e "engomação" (formas de ganhar tempo) junto aos internos que reclamam dos atrasos em cada um dos procedimentos descritos acima. Nessas situações, saber negociar, ou como diria na linguagem da prisão, saber "engomar", é uma das estratégias que mantêm a rotina sem que seja necessária uma intervenção mais dura.

O encontro do familiar com o interno é marcado por fortes emoções. O abraço apertado aconchega corpos que por algum tempo não se reencontram. Naquele momento, termina o itinerário de revistas e vistorias que teve início com a conferência da documentação para a confecção da carteirinha. Naquele dia, as conferências iniciaram com Marcela na recepção e se estenderam com a "vistoria dos malotes", regulação das roupas, pela "revista pessoal" e por mais uma conferência dos documentos no quadrante 1 . Por fim, tudo foi radiografado através de ritualísticas específicas em cada etapa do exame meticuloso dos documentos, comidas, objetos, acessórios, roupas e corpos.

Padovani (2018) relata as diferentes maneiras como fora pessoalmente revistada nas prisões. Para ela, os modos como eram executadas as revistas se diferenciavam a partir dos múltiplos vínculos que ela manteve nas unidades prisionais. No decorrer de sua imersão em campo, a pesquisadora teve a anuência para ingresso em algumas penitenciárias de São Paulo e Catalunha como antropóloga, como agente da Pastoral Carcerária e como visita familiar. Cada processo de revista era acionado em função dos documentos que carregava em cada situação. Como antropóloga, a revista se dava no âmbito das perguntas que desafiavam a produção do saber por alguém externo à instituição. Como agente da Pastoral, a revista era centralizada no controle das roupas, acessórios e objetos que carregava consigo, tensionados pelos pontos divergentes entre a função de agente da Pastoral e a de agente de segurança a respeito dos direitos humanos. Enquanto visita familiar, foi submetida à "revista vexatória". Para a autora, a radicalidade da revista em familiares é tensionada pelo antagonismo produzido nas relações entre agentes penitenciários e presos no cotidiano da prisão. Ou seja, entrar em uma unidade prisional como visita familiar "é estar em posição de justaposição ao preso na relação com os funcionários da prisão" (p. 88). A antropóloga chama a atenção para a pressuposição de que os familiares, sozinhos, sejam responsáveis pela entrada de drogas e celulares na prisão, enquanto advogados, pesquisadores, funcionários e voluntários não levantem tantas suspeitas. Mais do que a suspeita em relação aos familiares, Padovani chama a atenção para uma justaposição entre presos e familiares exposta na forma como os agentes revistam seus corpos e objetos. 
Luzia, agente penitenciária responsável pela revista em visitantes da PIRS, falou de como as visitantes querem tirar vantagem em qualquer situação e do desapreço que sente por elas. Para a interlocutora, a vistoria das visitantes é muito pior do que "tirar plantão" custodiando os presos: "Elas se acham donas da verdade, se vitimizam e querem tirar vantagem em tudo. Reclamam de todo o procedimento de vistoria e ameaçam denunciar na Defensoria Pública. Trabalhar com presos é ainda melhor que trabalhar com elas!”.

Luzia disse perceber que em algumas situações as visitantes estão falando a verdade e também se compadece com a situação de vulnerabilidade de algumas delas. Além da justaposição entre presos e visitantes apontada por Padovani (2018), o relato de Luzia nos permite perceber que seu desapreço pelas visitas está ligado à insubmissão durante o passo a passo dos "procedimentos". Dito de outro modo, à capacidade de resistência ao disciplinamento institucional, justamente por não estarem na condição de total submissão aos aparatos estatais, a exemplo de seus parentes privados de liberdade. Ao contrário dos internos, que dispõem apenas de outros profissionais responsáveis pela segurança prisional como canal de comunicação imediato, visitantes podem recorrer a outras instâncias a fim de denunciar excessos, irregularidades ou violações de seus direitos enquanto familiares de presos.

Ao encarnar a regulação da entrada das visitantes e tentar mitigar processos argumentativos que possam borrar hierarquias, Luzia incorpora o Estado (MARQUES et al., 2014). A presença da agente, seus argumentos e conduta instituem a existência micropolítica do Estado através da tentativa de seus profissionais agirem de forma a reafirmar as fronteiras do "fora X dentro" da prisão como realidade autoevidente. Tais fronteiras nos parecem uma forte alegoria da presença $\mathrm{e}$ racionalidade do Estado tal qual reapresentado a partir do sistema prisional.

\section{Fluxos e circulação de materiais "permitidos" e "ilícitos" nas celas}

Poderíamos dizer que sob o ponto de vista do movimento feminista, a substituição da "revista íntima" pela revista eletrônica possibilitou um exame menos invasivo das visitantes que adentram as unidades prisionais do Ceará. Sob o ponto de vista do Estado, a tecnologia estabeleceu verificação mais rigorosa do material que ultrapassa as fronteiras das prisões.

A racionalidade do Estado e suas regulações passam a ser materializadas por uma relação objetiva, transparente e tecnológica, ao invés de mediada intersubjetivamente na relação entre agentes e visitantes. Em certa medida, a conjunção das vozes dos direitos humanos, dos movimentos feministas e da vontade de controle de fronteiras pelo Estado se consuma através do olhar absoluto do raio X. Olhar imparcial que atravessa o opaco.

A despeito desses significados conjugados, as tecnologias de Estado nas fronteiras das prisões nem de longe cessaram a tensão sobre a inserção de "materiais ilícitos", como drogas, aparelhos celulares e armas. Na tabela a seguir, vemos dados referentes à apreensão de "materiais ilícitos" em estabelecimentos prisionais do Ceará entre 2014 e 2016. 
Tabela 1 - Apreensões de ilícitos nas unidades prisionais do Ceará nos anos de 2014 a 2016

\begin{tabular}{lcrrrrrrr}
\hline APREENSÕES & \multicolumn{2}{c}{$\mathbf{2 0 1 4}$} & \multicolumn{2}{c}{$\mathbf{2 0 1 5}$} & $\mathbf{2 0 1 6}$ & GERAL \\
\hline MATERIAIS & MEDIDA & APRC & APRV & APRC & APRV & APRC & APRV & TOTAL \\
Faca & Unidade & 102 & 1 & 144 & 2 & 126 & 0 & 375 \\
Cossoco & Unidade & 1274 & 0 & 1013 & 0 & 360 & 0 & 2.647 \\
Estilete & Unidade & 4 & 0 & 0 & 0 & 8 & 0 & 12 \\
Tesoura & Unidade & 59 & 0 & 165 & 0 & 24 & 0 & 248 \\
Barra de ferro & Unidade & 244 & 0 & 40 & 0 & 52 & 0 & 336 \\
Pistola & Unidade & 1 & 0 & 0 & 0 & 4 & 0 & 5 \\
Revólver & Unidade & 0 & 1 & 1 & 0 & 19 & 0 & 21 \\
Munição & Unidade & 14 & 5 & 1 & 0 & 327 & 0 & 347 \\
Celular & Unidade & 6285 & 295 & 5881 & 16 & 4490 & 16 & 16.983 \\
Tablet digital & Unidade & 0 & 0 & 0 & 0 & 2 & 0 & 2 \\
Bateria de celular & Unidade & 2184 & 137 & 2365 & 2 & 1018 & 7 & 5.713 \\
Carregador de celular & Unidade & 2278 & 64 & 2885 & 1 & 1755 & 5 & 6.988 \\
Cartão de memória & Unidade & 79 & 6 & 101 & 1 & 139 & 0 & 326 \\
Chip & Unidade & 4308 & 532 & 5302 & 119 & 4552 & 125 & 14.938 \\
Maconha & Gramas & 45511 & 4340 & 71803 & 2941 & 55415 & 387 & 180.397 \\
Crack & Gramas & 4935 & 445 & 1449 & 57 & 1221 & 84 & 8.191 \\
Cocaína & Gramas & 3811 & 1152 & 1537 & 279 & 3997 & 100 & 10.876 \\
Psicotrópico & Unidade & 4442 & 1295 & 1759 & 0 & 1895 & 0 & 9.391 \\
\hline
\end{tabular}

Fonte: Secretaria de Justiça e Cidadania (CEARÁ, 2010).

A enorme variedade de tamanho e forma do material apreendido, bem como a disparidade entre "material ilícito" apreendido com as visitantes nas entradas das unidades (APRV) e do material apreendido nas celas (APRC) sugerem a existência de outras vias de ingresso não pontuadas pelo relatório.

Recorramos a algumas situações de campo em que a presença de objetos considerados proibidos nas unidades prisionais do Ceará foi ressaltada. A partir dos relatos, compreenderemos melhor o lugar dos "ilícitos" nas relações entre presos, entre familiares e presos e, finalmente, entre presos e profissionais das unidades.

Falando sobre a entrada e o uso de drogas na PIRS, Renata, travesti de 33 anos, que, no momento da entrevista, cumpria pena em regime aberto, nos diz que:

As drogas entravam pelas visitas nas partes íntimas. Depois que as visitas entravam na penitenciária as drogas apareciam na ala, por isso eu afirmo que eram elas que levavam. Não são todas, mas algumas levavam (...). Tinha também muita dívida de drogas em que as visitantes eram obrigadas a levar as drogas no corpo. As vezes até se prostituía para pagar a dívida do companheiro. 
De acordo com Renata, a principal forma de entrada das drogas na PIRS era através das visitantes, que conseguiam adentrar a unidade com substâncias. Amanda, travesti de 29 anos que cumpria pena em regime semiaberto por tráfico de drogas, confirma a entrada de drogas pelas visitantes, mas inclui também a corrupção de policiais, agentes penitenciários, funcionários terceirizados e presos que trabalham na cozinha: "As mulheres dos presos levam as drogas tanto na vagina como no ânus e retiram no banheiro da cela. Depois do raio X ficou mais difícil de entrar por elas. Mas também tem alguns agentes, policiais e o pessoal da cozinha que são aliados". Priscila, travesti presa por tráfico, que cumpria pena em regime fechado na PIRS, relata que por conta de seu vício em crack e dívidas de drogas passava por situações constantes de violência e extorsão de familiares. No presídio Irmã Imelda Lima Pontes ${ }^{7}$, Dayse comenta que já chegou a ganhar quatro mil reais por mês aplicando golpes através de aparelhos celulares. Todo o dinheiro era repassado ao traficante para quitar dívidas de drogas. Ainda sobre o uso de aparelho celular, Erika, travesti interna do Centro de Execução Penal e Integração Social Vasco Damasceno Weyne (CPIS) ${ }^{8}$, relata que mantém contato com seus familiares, com seu companheiro e amigos que estão fora da prisão. Afirma que é comum a compra, venda e aluguel desse meio de comunicação na ala onde é mantida aprisionada. Mas, a possibilidade do uso das tecnologias em penitenciárias também informa hierarquias e diferenças de poder de consumo entre presos e presas, pois os "papagaios" e outros equipamentos tecnológicos chegam a ter seu custo exponencialmente multiplicado na prisão.

Podemos perceber, portanto, como objetos considerados "ilícitos" dinamizam diferentes formas de sociabilidade no interior das unidades, não sendo incomum relações de violência e conflito operadas a partir do mercado das drogas. O uso de aparelhos celulares e armas ocupam lugar de destaque nas diversas formas de extorsão de presos por outros presos, bem como de familiares de presos por pessoas relacionadas às facções fora das unidades prisionais.

Como o dinheiro é proibido no interior das unidades, alimentos trazidos pelas visitantes, objetos de uso cotidiano ou depositados no almoxarifado, tais como: aparelhos de ventilador, televisão, rádio, roupas e tambores para armazenamento de água acionam formas de negociação não ordinárias. Serviços prestados por presos a outros presos, chamados "corres", como: extorsões via celular, atividades domésticas e sexuais, também ocupam lugar nesse mercado de trocas sem dinheiro.

Em algumas unidades prisionais, principalmente em cadeias públicas onde a vigilância é frágil, existe outra forma de negociação. Nestas prisões, a ausência do número suficiente de agentes penitenciários dá margem ao surgimento da figura dos "presos de confianças" - internos responsáveis por várias funções administrativas e que, em muitas ocasiões, abrem e fecham os

\footnotetext{
7 A Unidade Prisional Irmã Imelda Lima Pontes, inaugurada em 2016, está localizada na Região Metropolitana de Fortaleza. Com capacidade para 200 internos e internas, o espaço aprisiona pessoas deficientes, idosos, gays, bissexuais, travestis, transexuais e primários de crimes prescritos na Lei Maria da Penha.

8 A CPIS foi inaugurada em 2016. É a maior penitenciária do Ceará com capacidade total para 1.016 internos. No período de imersão em campo, a unidade abrigava 1.937 pessoas em cumprimento de pena.

9 "Papagaio" ou "rádio" são as designações utilizadas pelos presos para se furtar da palavra celular.
} 
portões das celas supervisionados por um único agente penitenciário plantonista. Esses detentos têm acesso pouco vigiado entre o espaço externo e interno da prisão, cobrando para "botar cada celular pra dentro" da unidade prisional.

Fora o mercado de compra e venda de celulares, há também compra e venda de ligações e aluguéis dos celulares por tempo determinado. O preço do celular, o custo de uma ligação e o valor do aluguel variam entre as unidades prisionais, observada a facilidade ou não do acesso a essa tecnologia. $\mathrm{O}$ alto custo da aquisição ou aluguel de um celular na prisão diz muito a respeito dos riscos que corre quem facilita a entrada ou mantém a posse do aparelho no interior da cela. A lei 11.466/2007 proíbe o uso de aparelhos celulares nos presídios e define como falta grave a posse de aparelho que permita a comunicação com outros presos ou com o ambiente extramuros. Se o preso ou a presa for flagrado com um aparelho celular está sujeito a sanções de permanência de até um mês no regime disciplinar, cessação de visitas, perda do trabalho e de toda a remição de pena acumulada até então, e suspensão, durante os seis meses seguintes, de pedidos de liberdade condicional e de progressão de regime (BUMACHAR, 2012).

A problemática em torno da apreensão de celulares nas unidades prisionais do Ceará nos últimos três anos informa como o uso desta tecnologia se disseminou entre os internos, seja para fins de contato com familiares, amigos e companheiros "da liberdade" ou para obter vantagens com a prática de golpes. Por outro lado, o Estado tem investido em novas regras e metodologias para inibir o fluxo de celulares nas prisões.

Ao longo da pesquisa em campo, alguns agentes penitenciários e gestores relataram que a possibilidade de entrada de drogas, celulares e armas de fogo nas unidades prisionais é a principal justificativa para o rigor das revistas em visitantes e seus "malotes". Ressaltaram os transtornos e riscos que esses materiais podem trazer para o cotidiano de trabalho na prisão.

No tocante aos objetos e substâncias apreendidos com as visitantes nas unidades prisionais do Ceará, temos as seguintes porcentagens médias correspondentes ao acumulado de 2014, 2015 e 2016: celulares 1,92\%, maconha 4,25\%, crack 0,71\%, cocaína 14,07\% e armas de fogo 3,84\%. Esses dados mostram que é insustentável o argumento de que grande parte dos "materiais ilícitos" atravessa as fronteiras das prisões através dos corpos das visitantes. Não estamos afirmando aqui que estas não estejam implicadas como meio de transporte, por associação ou coerção, no abastecimento de "materiais ilícitos" nas unidades. Antes, os dados apontam que elas são sim responsáveis por parte da entrada desses materiais na prisão, mas não as principais, como sustentam as rígidas práticas de revista a familiares que visitam as prisões.

A utilização da revista eletrônica, como apontado por Amanda, inibe as tentativas de atravessar as fronteiras da prisão com "ilícitos" encaixados em cavidades ou escondidos em "malotes". Por outrolado, "rebolos" por cima das muralhas e a corrupção de profissionais passaram a compor a trama cotidiana das unidades prisionais, principalmente, após o espraiamento das facções no interior das prisões e fora delas. Exploraremos este assunto nas cenas apresentadas na sessão a seguir. 


\section{Os Limites do Estado e os binarismos de fronteiras}

Em junho de 2016, reportagens sobre a crise penitenciária no Ceará foram veiculadas na imprensa nacional. A divulgação de dois vídeos, gravados e publicados por internos em redes sociais, mostram cenas de uma festa intitulada "Baile de Favela" ocorrida em prisão da Região Metropolitana de Fortaleza. Nas imagens, detentos são filmados utilizando drogas e bebidas alcoólicas, comunicando-se por aparelhos celulares e dançando ao som de músicas bastante populares do ritmo conhecido como forró eletrônico. Enquanto se divertem, referem-se a outros internos presentes no "Baile" a partir de suas filiações a facções criminosas ${ }^{10}$. Em 17 de janeiro de 2018, o jornal Diário do Nordeste veiculou reportagem sobre a prisão de três pessoas, dentre elas uma agente penitenciária, suspeitas de participar de um esquema para o ingresso de celulares no interior da CPIS (DIÁRIO DO NORDESTE, 2018).

É possível imaginar que na manhã daquele mesmo dia de junho de 2016, agentes penitenciários desdobraram-se em estafante rotina de revista e vistoria das visitantes para evitar que algum "material ilícito" cruzasse as fronteiras das unidades prisionais do estado. Paralelo a isso, ao longo dos dois últimos anos, temos acompanhado recorrentes tentativas de arremessos de drogas, bebidas alcoólicas, celulares e outros aparelhos eletrônicos por cima do muro da PIRS (NASCIMENTO, 2015).-

Um ano após o "Baile de Favela”, no "Encontro de Governadores do Brasil pela Segurança e Controle das Fronteiras: Narcotráfico uma Emergência Nacional", ocorrido em Rio Branco (AC) em outubro de 2017, o governador do estado, Camilo Santana, afirmava que as facções criminosas se alastraram de tal forma que o estado do Ceará não consegue sequer conter a entrada de celulares nos presídios, quiçá impedir os índices de assassinatos e outros indicadores da violência.

A colagem dessas cenas permite perceber como a manifestação da própria existência do Estado se ancora na performance das revistas descritas acima. Força e rigor demonstrados por agentes femininas e masculinos para regular as fronteiras do dentro $\mathrm{x}$ fora das unidades prisionais como espaço de contágio. Supostamente, caso as verificações dos postos fossem realizadas com o rigor necessário, este espaço se revelaria como espaço uniforme e racionalmente regulado. Como afirmamos acima, a fronteira revela-se como esse lugar onde o Estado produz uma imagem de regulação e dá-se a ver a si mesmo.

Por outro lado, sob o ponto de vista do tráfico e do comércio ilegal de materiais ilícitos, a presença, força e rigor das facções é demonstrada pelo poder de atravessar espaços supostamente regulados, fazer-se presente pela sua vontade, a despeito da vontade do Estado.

A fronteira é assim espaço de disputas: de um lado, sua espetacularização e poder de administração pelo Estado, de outro, capacidade de subversão e ubiquidade pelo tráfico. Vale

10 Vídeos disponíveis em: <https://www.youtube.com/watch?v=fmHgtIXH2So $>$; $<$ https://www.youtube.com/watch? $\mathrm{v}=$ mdiLFGDzUxk $>$. 
perceber como essa tensão de gramáticas se estabelece a partir de uma polissemia sobre fronteiras e corpos, notadamente sobre os corpos femininos. Retomando Foucault, Butler (2014) chama a atenção para a relação entre regulação e formas de subjetivação:

É importante relembrar pelo menos duas advertências sobre sujeito e regulação derivadas das pesquisas foucaultianas: (1) o poder regulador não age apenas sobre um sujeito pré-existente, mas também delimita e forma esse sujeito; além disso, toda forma jurídica de poder possui efeito de produção; e (2) tornar-se sujeito de uma regulação equivale a ser assujeitado por ela, ou seja, tornar-se sujeito precisamente porque foi regulado (BUTLER, 2014, p. 252).

A gramática dos pronomes, artigos, designações a que fomos submetidos, como autores, na escrita desse artigo ${ }^{11}$ para descrever sujeitos sempre gendrados, demonstra que fronteiras do Estado dependem de conformação de sujeitos a partir de corpos masculinos e femininos. Nesta linha de argumentação, os processos de Estado, exemplificados nos controles desde pontos de verificações, longe de serem entendidos apenas como burocracias das prisões, são representados como matérias vivas nas práticas, atributos e representações de gênero, pensados também em sua carnatura desde seus qualificativos morais e sua capacidade de moldar, limitar e produzir desejos e horizontes de possibilidade (VIANA; LOWENKRON, 2017).

Trânsitos de sujeitos diferenciados por artigos que qualificam gênero: as agentes, as mães, as filhas; a variação na frequência e caráter das visitas masculinas e femininas nas unidades prisionais; a descrição das visitantes a partir de suas cavidades; todos esses exemplos demonstram práticas de Estado inspiradas em uma gramática binária, conformando diferenças e hierarquias entre corpos masculinos e femininos, conforme demostrado em políticas públicas diversas (LIMA, 2002). Em texto recente, Vianna e Lowerkon (2017) demonstram que embora o Estado opere sobre corpos generificados suas configurações de gênero são bem mais complexas que a mera oposição entre um Estado masculino contra um assujeitamento feminino. Para as autoras:

(...) a ideia de Estado e as formas de poder por ele exercidas e engendradas, mesmo que quase sempre imaginadas como masculinas, articulam-se a versões ou atributos de gênero distintos, contribuindo, assim, para a conformação de diferentes constructos de masculinidade e, poderíamos acrescentar, de feminilidade (e175101).

Pudemos perceber acima que essa gramática acessa múltiplos sujeitos em posições sociais bastante variadas, evidenciando aquilo que Foucault (1997) nomeou como microfísica do poder: são agentes prisionais identificadas com o Estado; travestis que atribuem às cavidades femininas o ir e vir de mercadorias pelas fronteiras; corpos femininos tomados como visitantes preferenciais por sua condição de mãe, filha ou parente próxima, desde que o parentesco seja 
atestado pelos órgãos competentes. Se corpos masculinos e femininos são fundamentais para operar as fronteiras do dentro e fora no trânsito de objetos, mercadorias e novas relações de poder delas advindas, essa gramática não seria possível sem outro binarismo, assinalado aqui como oposição "pureza x contágio" (DOUGLAS, 1991). A partir dele, a integridade das fronteiras aparece como encarnação do Estado, em oposição ao contágio das visitantes, usualmente no feminino. Corpos femininos que atravessam fronteiras seriam, portanto, duplamente perigosos. Em princípio, como nos fez ver Padovani (2018), por uma justaposição entre familiares de presos e o mundo do crime, mães, filhas, esposas são cuidadoras, sempre femininas, preferenciais do Estado. São também corpos suspeitos por compartilharem com internos origem social, vínculos familiares, marcadores étnicos e raciais. Por outro lado, são esses corpos, a um só tempo cuidadores e suspeitos, que terão suas cavidades revistadas rigorosamente ou escaneadas pelo olho do Estado. Na equação da fronteira das unidades prisionais o feminino é reiterado como vetor de suspeita e contágio, devendo submeter cavidades, documentos e malotes ao olho abrangente do Estado - raio $\mathrm{x}$.

Configura-se, portanto, nas fronteiras das unidades prisionais, uma conformação intersecional de poderes, capazes de operar uma forma de objetivação fundamental para o Estado compor-se como local insuspeito. Em oposição ao contágio do mundo do crime, operado por corpos femininos, um Estado rigoroso, esforçado e íntegro. Essa objetivação entre corpos que se misturam esquadrinhados por corpos uniformizados em postos de verificação não seria possível sem corpos, gêneros e fronteiras.

\section{Considerações finais}

Como aprendemos com Foucault $(1997,2015)$, o governo penitenciário exerce poder sobre as pessoas, em suas relações com outras pessoas e com objetos. Define o que é "permitido" e o que é "proibido", valida regalias em oposição a direitos; regula fluxos de pessoas, objetos e informações; institui locais e "procedimentos" de verificação; treina a mecânica dos corpos dos profissionais para um total aproveitamento de suas forças; vigia, monitora e penetra as subjetividades de presos e agentes penitenciários. A positividade dessa engenharia, no entanto, depende de suas objetivações. Tentamos perceber aolongo do artigo como processos de Estado acionam binarismos que localizam, atualizam, conformam, encarnam e fetichizam posições. As fronteiras aparecem, portanto, como campo produtivo para a análise das relações deflagradas a partir do Estado (ALBUQUERQUE; OLIVAR, 2015; 2018; FELTRAN, 2011; GODOI, 2015b; PADOVANI, 2018).

Para tanto, seguindo alguns exemplos das literaturas clássica e contemporâneas do campo, convencionamos pensar Estado a partir de sua carnatura, dos processos pelos quais torna visíveis suas gramáticas (RAMALHO, 1983; FELTRAN, 2011; PADOVANI, 2018). À porta da Penitenciária Industrial Regional de Sobral, a partir da extenuação de recursos físicos e financeiros das visitantes, dos esforços dos agentes e das tecnologias para conformação do Estado 
pela gramática dos direitos humanos, estabelece-se uma performance da impenetrabilidade do Estado. A descrição desses processos requer empatia com as pessoas que cotidianamente se submetem a ele. Empatia pela observação ou não das gramáticas de gênero, de etnia e de classe operadas a partir da ação de verificar e ser verificada. Será possível reter essa gramática sem a ela submeter-se? Se as performances de rigor do Estado às portas das unidades prisionais capturam nosso olhar, o que se invizibiliza pela ação cotidiana desse processo de Estado?

Ao longo desse artigo, acionamos artigos jornalísticos, vídeos produzidos por internos, termos nativos utilizados nas unidades prisionais, além do valor de alguns objetos considerados "ilícitos". A partir dessa variedade de fontes, aproximamo-nos de pontos de fuga embotados pela performance do Estado às portas das unidades. Percebemos que relações entre presos e profissionais ou prestadores de serviços nas unidades, "rebolos", entre outras ambiguidades, tem lugar privilegiado na disputa em curso entre a intangibilidade do Estado versus a ubiquidade do crime. Disputa materializada através da presença e valorização de objetos ilícitos para além dos limites ditados pelo Estado.

À despeito dessa variedade de tensões, ações e hierarquias, a objetivação dessa disputa parece capturar olhares de familiares, operadores do Estado e etnógrafos para o cotidiano das fronteiras e as marcas sociais presentes nos corpos que por ela atravessam. A fim de qualificar nosso olhar, impõe-se, portanto, perceber fronteiras institucionais como enredo performático, mais que local privilegiado de um iminente contágio.

Ao longo do artigo, o lugar abjeto (BUTLER, 2008) das travestis em prisões masculinas foi também acionado como lugar errático de produção de significados sobre fronteiras e “ilícitos". Se, por vezes, travestis são objetos de desejo ou repulsa preferencial de companheiros de prisão (NASCIMENTO, 2018), se, por vezes, a circulação de performatividades femininas em prisões masculinas coloca suas vidas em risco, seus corpos incomuns na gramática comum cis-heteronormativa produz reflexões sobre o lugar dos binarismos de gênero (BUTLER, 2008) no espaço prisional. Das aproximações entre performances travestis e o feminino decorrem parcerias sexual-afetivas no cotidiano da prisão, relega-se para elas papéis como: trabalhadoras sexuais, realizadoras de trabalhos domésticos no interior das celas, entre outros. No limite da tematização sobre a entrada e manutenção de objetos considerados ilícitos nas unidades prisionais presente nesse artigo, vale perceber que travestis não fazem visitas a presos e presas. Que a partir dos binarismos demonstrados ao longo do artigo, suas cavidades são constantemente colocadas em suspeita. A impossibilidade de apreendê-las a partir de polos fixos entre masculino e feminino as compõe como sujeitos sempre suspeitos. Ao mesmo tempo, tal ambiguidade não implica que corpos travestis não reiterem ocasionalmente as ações performáticas do Estado, em seus jogos de polarizações. Como vimos acima, Renata aponta vaginas como fontes prioritárias de circulação de ilícitos, abrandando falas que denunciam outras tensões existentes no cotidiano prisional que não aquelas que instituam a relação masculino $\mathrm{x}$ feminino como lugar de hierarquia e das prisões como local de iminência de contágio. 
A análise da complexa relação entre o dentro e o fora da prisão parece avançar quando passamos a considerar a força performativa presente no cotidiano dos agentes, a presença de objetos ilícitos como materialização de disputas e hierarquias e, finalmente, as gramáticas de gênero e sexualidade como fontes incontornáveis para a reflexão sobre o Estado.

Como demonstrado por Lago e Zamboni (2018), Efrem Filho (2017), Nascimento (2015) e Ferreira (2014), o entrecruzamento entre os campos de sociologias das prisões e os estudos de gênero e sexualidade, a partir da descrição de processos de Estado, revela-se como área relevante na renovação de fontes e alternativas metodológicas para as Ciências Sociais.

\section{Referências}

Agente penitenciaria é presa por corrupção e associação criminosa. Diário do Nordeste, Fortaleza, 17 jan. 2018. Disponível em: http://diariodonordeste.verdesmares.com.br/cadernos/policia/online/agente-penitenciaria-e-presa-por-corrupcao-e-associacao-criminosa>. Acesso em: 24 jan. 2018.

ALBUQUERQUE, J.L.; OLIVAR, J.M. N. Apresentação do Dossiê Fronteiras: territórios, políticas, diferenças e desigualdades. Revista Ambivalências, Aracaju, v. 3, n. 5, p. 3-27, jan./jun. 2015.

BRASIL. Decreto-lei no 2.848, de 7 de dezembro de 1940. Código Penal. Disponível em: < http://www.planalto. gov.br/ccivil_03/decreto-lei/Del2848compilado.htm>. Acesso em: 05 jul. 2016.

BRASIL. Ministério da Justiça. Departamento Penitenciário Nacional. Levantamento Nacional de Informações Penitenciária INFOPEN: julho de 2016. Brasília, DF: Ministério da Justiça, 2016. Disponível em: <http://depen. gov.br/DEPEN/noticias-1/noticias/infopen-levantamento-nacional-de-informacoes-penitenciarias-2016/relatorio_2016_22111.pdf>.Acesso em: 24 abr. 2018.

BUTLER, J. Cuerpos que importan. Buenos Aires: Paidós, 2008.

BUTLER, J. Regulações de gênero. Cadernos Pagu, Campinas, n. 42, p. 249-274, jun. 2014 .

BIONDI, K. Junto e misturado: uma etnografia do PCC. São Paulo: Terceiro Nome, 2010.

BUMACHAR, B. Por meus filhos: usos das tecnologias de comunicação entre estrangeiras presas em São Paulo. In: COGO, D.; ELHAJJI, M.; HUERTAS, A. (org.). Diásporas, migrações, tecnologias da comunicação e identidades Transnacionais. Barcelona: Institut de la Comunicació, Universitat Autònoma de Barcelona, 2012. p. 449-468.

CARDIN; E.; ALBUQUERQUE, J. L. Fronteiras e deslocamentos. Revista Brasileira de Sociologia, São Paulo, v. 6, n.12, p.114-131, jan./abr. 2018.

CEARÁ. Lei Estadual de no. 14.966, de 13 de julho de 2011. Disponível em: <http://www.al.ce.gov.br/legislativo/ legislacao5/leis2009/14582.htm>. Acesso em: 3 nov. 2014.

CEARÁ. Portaria de n⿳0 0240/2010. Regimento Geral dos Estabelecimentos Prisionais do Estado do Ceará. Fortaleza, CE: Secretaria de Justiça e Cidadania, 2010.

CLIFFORD, J. Sobre a autoridade etnográfica. In: CLIFFORD, J. A experiência etnográfica. Rio de Janeiro: Editora UFRJ, 2002. p.17-62.

CUNHA, M. Prisão e sociedade: modalidades de uma conexão. In: CUNHA, M. Aquém e além da prisão: cruzamentos e perspectivas. Lisboa: 90 Graus, 2008. p. 7-32.

DAVIS, A. A Democracia da abolição. Rio de Janeiro: DIFEL, 2009.

DAS, V. Critical Events: An Anthropological Perspective on Contemporary India. New Delhi: Oxford University Press, 1995.

DAS, V.; POOLE, D. (org.). Anthropology in the margins of the State. Oxford, James Currency, 2004. 
Detento é suspeito de aplicar golpes em site de vendas e lesar mais de 30 pessoas. Segurança Pública, O Povo, Fortaleza, 17 fev. 2016. Disponível em: <https://www20.opovo.com.br/app/fortaleza/2016/02/17/noticiafortaleza,3576668/detento-e-preso-por-aplicar-golpes-em-site-de-vendas-e-lesar-mais-de.shtml>. Acesso em: 24 jan. 2018.

DOUGLAS, M. Pureza e perigo. Lisboa: Edições 70, 1991.

EFREM FILHO, R. A reivindicação da violência: gênero, sexualidade e a constituição da vítima. Cadernos Pagu, Campinas, v. 50, 175007, 6 jul. 2017. versão online. Disponível em: http://www.scielo.br/scielo.php?pi$\mathrm{d}=$ S0104-83332017000200308\&script=sci_abstract\&tlng=pt Acesso em: 22 ago. 2019.

FERREIRA, G. G. Violência, intersecionalidades e seletividade penal na experiência de travestis presas. Temporalis, Vitória, v. 14, n. 27, p. 99-117, 2014.

FELTRAN, G. Fronteiras de tensão: política e violência nas periferias de São Paulo. São Paulo: Editora Unesp: CEM: Cebrap, 2011.

FOUCAULT, M. Vigiar e punir. História da violência nas prisões. Petrópolis: Vozes, 1997.

FOUCAULT, M. A sociedade punitiva. São Paulo: WMF Martins Fontes, 2015.

GODOI, R. Fluxos em cadeia: as prisões em São Paulo na virada dos tempos. 2015. Tese (Doutorado em Sociologia) - Programa de Pós-graduação em Sociologia, Faculdade de Filosofia, Letras e Ciências Humanas, Universidade de São Paulo, São Paulo, 2015a.

GODOI, R. Vasos comunicantes, fluxos penitenciários: entre o dentro e o fora das prisões de São Paulo. Vivência: Revista de Antropologia, Natal, v.1, n. 46, p. 131-142, 2015 b.

GOFFMAN, E. Manicônios, prisões e conventos. São Paulo: Perspectiva, 1987.

LAGO, N.; ZAMBONI, M. Políticas sexuais e afetivas da prisão: gênero e sexualidade em tempos de encarceramento em massa. In: MALLART, F.; GODOI, R. BR 111 a rota das prisões brasileiras. São Paulo: Veneta/Le Monde Diplomatique, 2017. p. 71-86.

LIMA, A. C. S. (org.). Gestar e gerir: estudos para uma antropologia da administração pública no Brasil. Rio de Janeiro: Relume Dumará: NUAP/UFRJ, 2002.

MALlART, F.; RUI, T. Cadeia ping-pong: entre o dentro e o fora das muralhas. Ponto Urbe, São Paulo, n. 21, p. 1-17, ago./dez. 2017. versão online. Disponível em: https://journals.openedition.org/pontourbe/3620 Acesso em: 22 ago. 2019.

MARCUS, G.; CUSHMAN, D. Etnographies as texts. Annual Review of Anthropology, Palo Alto, USA, v. 11, p. 25-69, 1982.

MARQUES, R. et al. Incorporando o Estado em bairros periféricos: risco e mediação nas Equipes de Saúde de Família. In: ENCONTRO INTERNACIONAL VIOLÊNCIA E CONFLITOS SOCIAIS: TERRITORIALIDADES E NEGOCIAÇÕES, 4, 2014, Fortaleza. Anais do IV Encontro Internacional Violência e Conflitos Sociais. Fortaleza: LEV, 2014. p. 1-10.

NASCIMENTO, F. E. M. Entre grades, muralha e vivências: uma etnografia da ressocialização na Penitenciária Industrial Regional de Sobral. 2015. Trabalho de Conclusão de Curso (Bacharelado em Serviço Social) - Instituto Superior de Teologia Aplicada, Sobral, Ceará, 2015.

NASCIMENTO, F. E. M. Travestilidades Aprisionadas: narrativas de experiências de travestis em cumprimento de pena no Ceará. 2018. Dissertação (Mestrado Acadêmico em Sociologia) - Programa de Pós-Graduação em Sociologia, Universidade Estadual do Ceará, Fortaleza, 2018.

NASCIMENTO, F. E. M. Faç̧ões, rebeliões, violência e gestão do aprisionamento no Ceará. O público e o privado, Fortaleza, 2019. No prelo. 
NASCIMENTO, F. E. M.; FREITAS, G. J. No olho do furacão: notas sobre as mudanças na gestão do aprisionamento que provocaram a crise na segurança pública do Ceará. In: CONGRESSO BRASILEIRO DE SOCIOLOGIA, 19, 2019, Florianópolis. Anais do 19 $^{\circ}$ Congresso Brasileiro de Sociologia. Florianópolis: Universidade Federal de Santa Catarina, 2019. p. 1-30.

OLIVAR, J. M. N. Performatividades governamentais de fronteira: a produção do Estado e da fronteira por meio de políticas de tráfico de pessoas na Amazônia brasileira. Revista Ambivalências, Aracaju, v. 3, n. 5, p. 149-182, jan./jun. 2015.

PADOVANI, N. C. Sobre casos e casamentos: afetos e amores através de penitenciárias femininas em São Paulo e Barcelona. São Carlos: EdUFSCar, 2018.

PAIVA, L. F. “Aqui não tem gangue, tem facção”: as transformações sociais do crime em Fortaleza, Brasil. Caderno CRH, Salvador, v. 32, n. 85, p. 165-184, jan./abr. 2019.

RAMALHO, J.R. Mundo do crime. A ordem pelo avesso. Rio de Janeiro: Graal, 1983.

SÁ, L. D.; AQUINO, J. P, D. “Guerra das facções” no Ceará (2013-2018): Socialidade armada e disposição viril para matar ou morrer. In: ENCONTRO ANUAL DA ANPOCS, 42, 2018, Caxambu. Anais do $42^{\circ}$ Encontro Anual da ANPOCS. São Paulo: Anpocs, 2018. p. 1-30.

VIANNA, A.; LOWENKRON, L. O duplo fazer do gênero e do Estado: interconexões, materialidades e linguagens. Cadernos Pagu, Campinas, n. 51, 175101, 2017. versão online. Disponível em: http://www.scielo.br/pdf/cpa/n51/ 1809-4449-cpa-18094449201700510001.pdf Acesso em: 22 ago. 2019.

SPIVAK, G. Pode o subalterno falar? Belo Horizonte: Ed.UFMG, 2010.

STRATHERN, M. Necessidade de pais, necessidade de mães. Revista de Estudos Feministas, Florianópolis, v. 2, n. 3, p. 303-329, 1995.

Recebido em: 10/08/2018 